\title{
Imhotep renasce na sala de aula: a utilização do filme A Múmia (1932) no ensino de História do Egito
}

Imhotep is reborn in the classroom: the use of the film The Mummy (1932) in the Egypt History Teaching

\author{
Cristine Fortes Lia \\ Wellington Rafael Balém
}

Universidade de Caxias do Sul - UCS - Caxias do Sul - Rio Grande do Sul - Brasil

\begin{abstract}
Resumo: Tanto o ensino de História quanto o cinema como recurso didático, como fonte e como História têm sido amplamente debatidos atualmente, demonstrando o interesse e a importância dessas temáticas. Neste artigo discutimos o papel de um filme específico no ensino de História do Antigo Egito no processo de formação de professores. Para isso, analisamos as experiências de exibição e análise do filme " $A$ Múmia" (Universal, 1932) a partir das problemáticas levantadas pelos alunos da licenciatura em História da Universidade de Caxias do Sul. Partimos de algumas metodologias básicas para o uso de cinema em sala de aula e, então, entramos em aspectos mais específicos da exibição, do conteúdo e da análise de "A Múmia". Justificamos esta escolha por este ser um filme que consolidou a "múmia" no imaginário popular como uma personagem de terror e mistério, influenciando diretamente as dezenas de filmes sobre o tema produzidos até os dias de hoje. Defendemos, assim, a necessidade de uma abordagem que permita aos alunos estabelecerem relações dialógicas entre a historicidade das temáticas das quais 0 filme trata e a historicidade da obra em si, superando visões generalistas e reducionistas sobre determinados aspectos da história egípcia.
\end{abstract}

Palavras-chave: Ensino de História. Cinema. Antigo Egito.

\begin{abstract}
History teaching and Cinema as teaching resource, historical source, and history itself, is being widely discussed currently, demonstrating the interest and importance of these issues. This work discusses the role of a specific film in teaching History of Ancient Egypt in the teacher training process. For this, we analyze the display experiences of the film "The Mummy" (Universal, 1932) through some questions found by the History undergraduate students from University of Caxias do Sul. Firstly, we introduce some basic methodologies for the use of film in the classroom and then we discuss the specific aspects of the display, content, and analysis of "The Mummy". We justify this choice because it was a film that consolidated the "mummy" in the popular imagination as a character of horror and mystery. It also directly influenced most of films on the subject produced until today. We stand the need for an approach that allows students to establish dialogical relations between the historicity of the film themes and the historicity of the movie itself, overcoming general and reductionist views on certain aspects of Egyptian history.
\end{abstract}

Keywords: Teaching History. Cinema. Ancient Egypt. 


\section{Introdução}

Neste estudo, apresenta-se e discute-se o ensino de História do Egito a partir da exibição e análise de um filme específico: "A Múmia", dos estúdios da Universal, produzido em 1932. Este teve forte influência sobre produções posteriores e contribuiu ativamente para a consolidação da imagem atual da figura da múmia no cinema e no imaginário popular. Começa-se a análise com uma discussão do filme no contexto da história da egiptologia e da apropriação de elementos egípcios que o cinema fez, especialmente, mas não só, a partir da descoberta da tumba do faraó Thutankhamon.

Em seguida, apresenta-se uma proposta de exibição e análise que foi feita com diversas turmas do curso de Licenciatura em História da Universidade de Caxias do Sul, no Rio Grande do Sul, no período de 2006 a 2016. Partindo de pontos de análise propostos pela professora e de problematizações levantadas pelos alunos, realizase uma abordagem que evidencia a historicidade de alguns elementos culturais egípcios evocados no filme como forma de superar simplificações e reducionismo

Da mesma forma, por meio da experiência promovida com os discentes do curso de História, identifica-se o potencial de uma produção cinematográfica que, mesmo frágil em tecnologias contemporâneas, pode estimular o aprendizado sobre o tema proposto. O cinema na sala de aula constitui-se como uma estratégia importante, mas que necessita de um suporte didático realizado pelo professor de forma a atingir uma contribuição significativa para o aprendizado dos alunos.

\section{Uma múmia entre o cinema e o ensino de História}

O filme "A Múmia" foi lançado em 1932 pela Universal Studios. Consagrado como sucesso de bilheteria da época, com a atuação de Boris Karloff, um dos grandes atores do período. Conta a história do sacerdote Imhotep que, depois de ter sido mumificado no Egito antigo, foi trazido acidentalmente de volta a vida no início do século XX. O filme, produzido em preto e branco, tem 73 minutos de duração, foi exibido com censura de 16 anos e considerado gênero de terror.

Na narrativa do filme, Imhotep, após voltar à vida, impõe-se a missão de reencontrar sua amada, do antigo Egito, e transformá-la em uma múmia revivida como ele. Para isto, se utilizará de inúmeros artifícios, desde a prática de uma suposta magia da antiguidade egípcia, até a eliminação física dos seus oponentes. Elementos da trajetória histórica da civilização referida misturam-se a situações ficcionais.

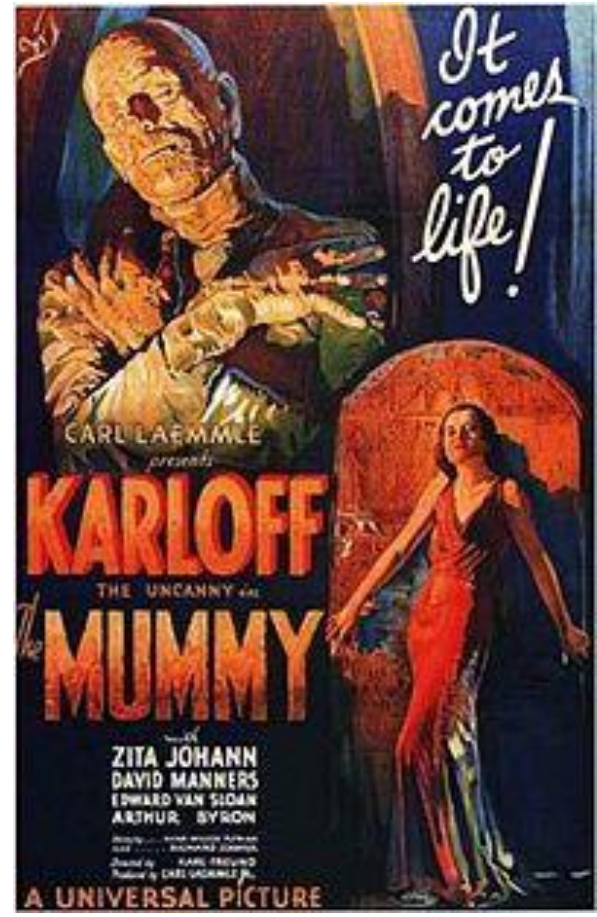

Figura 1: Cartaz do filme anunciando Karloff como protagonista e especificando que a múmia "retorna à vida".

Na História do Cinema, filmes de múmia não eram novidades na década de 1930. Segundo Basil Glyn (2004), filmes sobre o tema foram produzidos desde 1899, ainda em cinema mudo, sendo que alguns não sobreviveram aos nossos 
dias. Eles tiveram um período áureo entre as décadas de 1910 e 1920 e, então, experimentaram uma decadência. Bob Bryer acrescenta que, nestas primeiras décadas do século, "múmias eram figuras românticas, amantes que retornavam à vida para se reencontrar com seus amores reencarnados. Foi apenas com o papel clássico de Boris Karloff em 'A Múmia', em 1932, que o moderno conceito de múmia assumiu seu lugar no cinema" (2013, p.179). A partir desta época, a personagem múmia entra para 0 hall de personagens de terror, como Drácula e Frankenstein.

Sem dúvida, a descoberta da tumba do faraó Tutankhanon pelo arqueólogo Howard Carter, em 1922, contribuiu para o ressurgimento e a consolidação dos filmes de múmia. O evento foi coberto pela mídia por quase todos os países e as pessoas liam sobre 0 assunto quase que diariamente. Além disso, nos anos seguintes, as mortes em caráter misterioso das pessoas da equipe do Carter, só fez aumentar a demanda por esse mistério. Mas o interesse por "coisas" egípcias já era bastante antigo, incluindo em suas práticas a pilhagem em massa de artefatos para o exterior, sob interesses de museus e de indivíduos. Só foi possível iniciar um combate a essa situação com a criação de leis anti-pilhagem, do Serviço de Antiguidades Egípcias e do Museu de Nacional, em 1863.

O final do século $X I X$ e a primeira do $X X$ foi um período de intensas e numerosas expedições arqueológicas, já sob o controle das leis mais rígidas, técnicas arqueológicas mais adequadas e ao destino das peças escavadas, bastando ver o tratamento científico dado por Carter à tumba, em uma obra publicada em três volumes entre 1923 e 1933. Nesta época, a arqueologia egípcia se preocupava mais com o descobrimento de tumbas, com a escavação de estruturas em pedra e a busca por faraós e não se detinha em explorar assentamentos urbanos ou estruturas em tijolos, como os sítios de El-Amarna e Deir el-Medina (WEEKS, 2001, p.107-108). Assim, a maneira de ganhar prestígio e notoriedade social e científica era pela midiatização.

A cobertura da imprensa às descobertas de Carter e dos seus desdobramentos veio ao encontro de um interesse já consolidado a respeito da antiguidade egípcia ${ }^{1}$. O filme teve inúmeras continuações, refilmagens e derivações, umas com mais sucesso do que outras ${ }^{2}$. Tomando o referido filme como recurso didático e como fonte histórica, também cabe questionar sobre as razões da permanência das múmias no cinema. Segundo uma resenha de Menna El-Dory sobre o tema, muitas foram as tentativas de explicar esse fenômeno, sendo que,

uma das principais razões é o senso de imortalidade que permeia a história egípcia antiga. O desejo de imortalidade e o fascínio de uma vida exótica são as principais razões por trás da obsessão com a Egiptomania e também da forma pela qual ela é representada no cinema. (...) Talvez nada tenha um apelo mais universal do que mundos exóticos e eternos. O Antigo Egito foi um tema popular por causa dessa sua natureza atemporal, sendo que esta imortalidade foi disponibilizada em tempos modernos através do cinema. (s/d., p.1) ${ }^{3}$.

\footnotetext{
1 Sobre isso, basta citar o exemplo da Sala Egípcia da Biblioteca Pública de Porto Alegre, RS. Segundo Margaret Bakos, a sala, durante uma reforma, foi decorada com elementos de arte egípcia e inaugurada em setembro de 1922, dois meses antes da descoberta de Carter (BAKOS, 2001).

${ }_{2}$ Os filmes da Universal Studios que vieram depois podem ser descritos como continuações ou derivados, como The Mummy's Hand (1940) e suas continuações The Mummy's Tomb (1942), The Mummy's Ghost (1944), The Mummy's Curse (1944) e uma comédia-horror tardia Abbot and Costello meet the Mummy (1955). Filmes de múmia com a mesma ideia de roteiro foram produzidos na Inglaterra, pela Hammer Film Production, como The Mummy (1959) e suas continuações The Curse of the Mummy's Tomb (1964), The Mummy's Shroud (1966) e Blood from the Mummy's Tomb (1971) entre outros. Além destes, o remake recente da Universal Studios The Mummy (1999) e The Mummy Returns (2001) mostra que Imhotep ainda vive no imaginário das telas. Além disso, a Universal anunciou para 2017 mais um filme do gênero, mas, desta vez, a múmia será interpretada por uma mulher.

${ }^{3}$ El-Dorry credita uma natureza "atemporal" ao Antigo Egito. No entanto, os egípcios possuíam um forte senso temporal, possuindo, inclusive mais do que uma maneira de experienciar o tempo. Essa visão de um Egito idílico faz parte da construção colonial da historiografia e do cinema, que tenderam a fazer generalizações e simplificações sobre os traços culturais egípcios.
} 
Assim, o tema da religião egípcia em geral e da questão das múmias, em particular, que foi popularizado foi aquele de "A Múmia", de 1932, dentro de uma abordagem de suspense e terror. $\mathrm{O}$ pensamento religioso egípcio da antiguidade foi traduzido pela referida película, como cheio de mistérios e ocultismo. Os ritos funerários da referida civilização são caracterizados como algo místico e assustador. Assim, a religiosidade egípcia do mundo antigo começou a ser incorporada pela sociedade moderna envolvida de medo. Uma múmia é algo a se temer! O que fica muito explícito pelo olhar aterrorizante da personagem Imhotep.

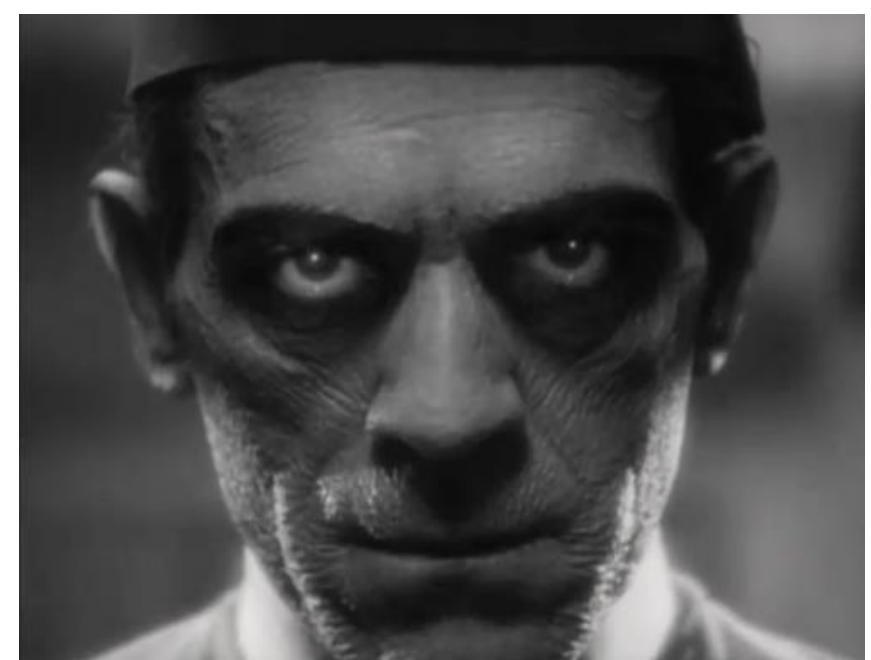

Figura 2: close no protagonista.

Discussões pertinentes a este período, como o possível caráter científico da História e o destino dos artefatos arqueológicos achados nas expedições, aparecem nos diálogos da produção cinematográfica. Apesar de não ter como proposta ser um filme sobre o conhecimento histórico, mas sim de terror, "A Múmia" se caracteriza pela presença de diversos elementos que possibilitam um diálogo profícuo com a História Antiga. Também permite a caracterização do entendimento sobre a cultura egípcia nas primeiras décadas do século $X X$, constituindo-se como fonte para o estudo sobre o tema.

Para Ferro (1992), "cinema é história" por promover a absorção de uma certa imagem transgressora da sociedade, pois permite compreender os mecanismos que promovem a consolidação de ideias que foram absorvidas com o passar do tempo. Para o autor, uma das estratégias para entender uma sociedade é conhecer as obras cinematográficas que a mesma produz.

\begin{abstract}
Para Ferro, o cinema é um testemunho singular de seu tempo, pois está fora do controle de qualquer instância de produção, principalmente o Estado. Mesmo a censura não consegue dominá-lo. O filme, para 0 autor, possui uma tensão que Ihe é própria, trazendo à tona elementos que viabilizam uma análise da sociedade diversa da proposta de seus segmentos, tanto o poder constituído quanto a oposição. (MORETTIN, 2011, p. 40)
\end{abstract}

A discussão sobre a relação entre cinema e História é intensa e ocupa teóricos da pesquisa e do ensino da área. Os historiadores cada vez mais potencializam a utilização de diversas linguagens para o ensino e a pesquisa. "Neste sentido, o cinema - incluindo todo o imenso conjunto das obras cinematográficas que já foram produzidas e também as práticas e os discursos que sobre elas se estabelecem - pode ser considerado, nos dias de hoje, uma fonte primordial e inesgotável para o trabalho historiográfico." (BARROS, 2012, p. 55)

Assim, em termos de ensino e pesquisa, o cinema deixou de ser um mero ilustrador dos contextos históricos e passou a ser agente da História. Barros (2012) identifica seis relações entre o cinema e a história, nas quais as produções cinematográficas podem ser fonte histórica, representação, instrumento para o ensino, linguagem e modo de imaginação aplicável, tecnologia de apoio para a pesquisa e agente. As películas consideradas com conteúdo histórico deixaram de ser prioridades para 0 trabalho do historiador, já que todas as produções representam algum tipo de contribuição para o estudo na área.

O cinema, enquanto imagens registradas em película, é um produto social. Todo filme, visto 
no interior de seu contexto de produção, é um filme histórico. Através do cinema, tem-se uma visão que nos possibilita enriquecer a compreensão das relações entre os aspectos sociais, políticos, econômicos e culturais de um contexto e o produto da criação cinematográfica. Ao mesmo tempo em que narra uma determinada visão da história, ele permite perceber pontos-de-vista diferenciados, retratando formas de contar um mesmo momento histórico. (CASTRO, BONOW, LUCAS, 2002, p. 165)

No que se refere ao ensino de História, o cinema (tanto ficcional, como de conteúdo histórico) também vem sendo abordado como meio para representação, objeto e fonte. As seis relações apontadas por Barros (2012) se reproduzem na pesquisa e no ensino. Desta forma, o filme A Múmia assume a função de estratégia, objeto e fonte para o ensino de História, pois além de possibilitar um diálogo entre o conhecimento adquirido pelos manuais oficiais e a linguagem cinematográfica, traduz $\mathrm{o}$ pensamento sobre $\mathrm{O}$ tema em uma época específica. Também permite compreender a historicidade do filme, analisando mudanças e permanências no pensamento sobre os temas da obra.

Para o professor utilizar o cinema na sala de aula, deve observar algumas estratégias fundamentais. Em primeiro lugar, o filme não pode ser exibido sem uma apresentação prévia. Não basta apenas anunciar o título, sem estabelecer considerações iniciais sobre a película que será apresentada e a sua relação com os conteúdos que estão sendo abordados. Para Barros (2012), toda a exibição de filme ou documentário em sala de aula deve passar por uma criteriosa preparação, na qual deve ser, inicialmente, realizada uma consulta prévia sobre 0 conhecimento dos alunos a respeito do que será exibido. Quem conhece o filme? Quantos já assistiram? Quando e como assistiram? Esses fatores serão sinalizadores das atividades de preparo para o entendimento da narrativa fílmica que o docente deverá realizar.
O professor deve, também, segundo Barros (2012), demonstrar conhecimento sobre o que será assistido e proporcionar mecanismos para que os alunos tenham um entendimento prévio do que será exibido. Para isto, um material de apoio deve ser fornecido aos discentes, no qual devem constar informações básicas sobre a película, como a sinopse, a duração, o ano de produção, a direção, eventual assessoria de especialistas no tema, além de outros dados relevantes. Esta ficha, como exemplifica o modelo abaixo, além de preparar a turma para uma compreensão mais ampla do que está por vir, rompe com algumas ideias preconcebidas sobre a narrativa. No caso do filme "A múmia", este material é fundamental para que a turma não se sinta desconfortável em assistir a uma produção que os alunos considerem ser obsoleta e desnecessária.

\section{Imhotep renascendo na sala de aula}

Depois de vários semestres de utilização do filme "A múmia" em sala de aula, em uma atividade que busca promover a articulação entre o conhecimento histórico desenvolvido na academia e na educação básica, os pontos de maior destaque na análise da produção estão focados nas questões sobre a trajetória do conhecimento histórico, dos erros e dos acertos da película.

Essa atividade corrobora na visão de que estratégias desenvolvidas nas aulas de licenciatura em História podem ser promovidas em turmas de Ensino Fundamental e Médio. Com a turma devidamente preparada, um filme em preto e branco, produzido na década de 1930, sem efeitos especiais e recursos tecnológicos, pode promover um aprendizado significativo. 


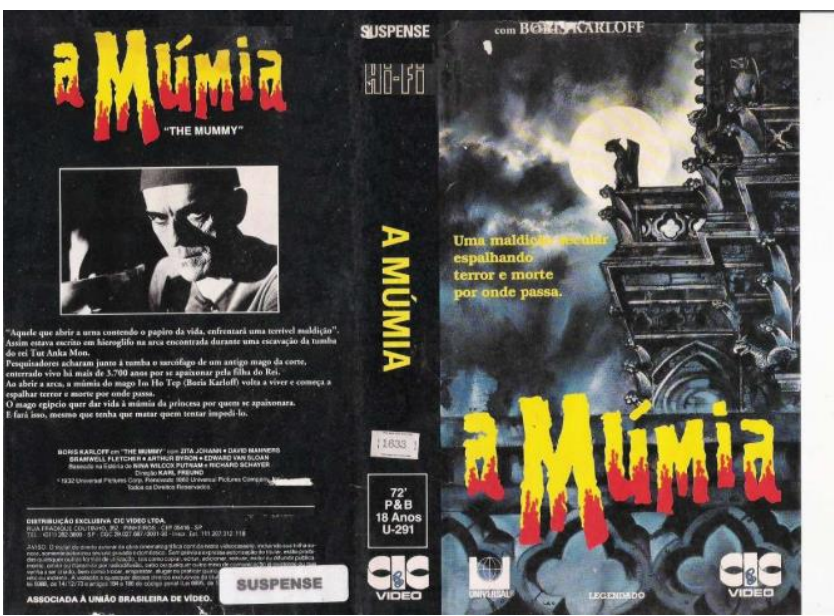

Modelo de ficha.

\section{"A MÚMIA"}

FILME DE KARL FREUND, UNIVERSAL STUDIOS, 1932.

Em 1921, uma equipe de arqueologistas no Egito, liderados por Sir Joseph Whemple (Arthur Byron), descobre a múmia do príncipe Imhotep (Boris Karloff), que vivera há 3.700 anos e que, por ter cometido um sacrilégio, teve como castigo ser enterrado vivo. Também foram encontrados manuscritos que tinham o poder de fazer os mortos ressuscitarem. Uma noite um dos membros da expedição lê os manuscritos e traz o príncipe de volta à vida. Após dez anos, Sir Joseph retorna com seu filho Frank (David Manners). Eles ignoram que Imhotep agora existe e se faz passar por Ardath Bay, um egípcio contemporâneo que ajuda a expedição que descobre a tumba do seu milenar amor, uma princesa que reencarnou em Helen Grosvenor (Zita Johann), uma bela e jovem mulher.

Foi refilmado em 1999, tendo também recebido o título de A Múmia

$\mathrm{Na}$ série cômica Chaves, no episódio "Filme de Terror", Chaves e Chiquinha assistem a esse filme que, na época, era um grande sucesso no México.

Atualmente, as imagens e os direitos do filme pertencem ao guitarrista do Metallica, Kirk Hammett.

Título original The Mummy

Ano de produção 1932

Tipo de filme longa-metragem

Orçamento 196000 \$

Idiomas inglês, francês, árabe

Formato de produção $35 \mathrm{~mm}$

Cor Preto \& Branco

Formato de áudio Mono

Formato de projeção $1.37: 1$

O professor também pode decidir se exibirá o filme com recortes ou completo. No caso de "A múmia", sugere-se a utilização da totalidade da produção ${ }^{4}$, já que tem duração de pouco mais de 70 minutos e o conteúdo pode não ser devidamente compreendido se exibido em pequenas partes. E, na preparação para o mesmo, o docente deve investir na ideia da qualidade de fonte histórica que a película apresenta, destacando seu potencial para compreender a sociedade egípcia, a narrativa fílmica do início do século $X X$ e as transformações do conhecimento histórico ao longo de um século. Sendo assim, também é importante que os alunos se apropriem de elementos próprios da História do Cinema para compreender, não só a linguagem cinematográfica do período e o quanto ela é diferente da atual, como também o contexto em que o filme foi produzido.

Merece destaque, nesta abordagem, questões relativas ao vocabulário conceitual. $\mathrm{Na}$ trama, Imhotep renasce através das palavras mágicas lidas por um jovem e ansioso arqueólogo. Uma vez renascido, a múmia busca reencontrar sua amada, a filha do faraó falecida na antiguidade, que teria reencarnado inúmeras vezes, até assumir o corpo da jovem Helen, na década de 1930. O conceito de reencarnação não tem relação com o pensamento religioso do antigo Egito. A ideia do pós-morte é a de renascimento e este aconteceria em um Egito igual ao que 0 indivíduo vivia. Da mesma forma, as crenças religiosas da antiguidade egípcia são denominadas

\footnotetext{
${ }^{4}$ Existe uma presente discussão sobre as questões referentes à utilização de filmes e documentários em sala de aula com a presença de cortes e edições realizadas pelo professor. Alguns autores consideram a estratégia válida, já que algumas produções apresentam uma duração de tempo que ultrapassa o desejável para a abordagem de determinado assunto. Outros teóricos do tema consideram estes cortes e edições uma escolha aleatória do docente, que pode comprometer 0 entendimento do conteúdo da produção cinematográfica. Além de não permitir que o aluno estabeleça as suas conclusões, por estar limitado ao recorte estabelecido pelo professor. Bem como, acreditam que somente na continuidade da narrativa, com todos os recursos de som e imagem, é possível consolidar um verdadeiro entendimento da mesma; caso contrário, assume postura tendenciosa, acrítica e ilustrativa. Sobre esta questão sugere-se a leitura das obras de Morettin (2001), Barros (2012) e Castro, Bonow e Lucas (2002).
} 
de ocultismo, de ciências ocultas; por isto o roteiro conduz a um filme de terror.

Um exemplo é a presença de um gato, no caso do filme branco e peludo, percebido como a presença da deusa Bast que, segundo a fala de uma das personagens, seria símbolo de mau agouro e morte. Segundo Wilkinson (2003), Bast foi representada de variadas formas ao longo da história egípcia. No Reino Antigo, com aspectos leoninos de fúria, ela aparece como mãe e cuidadora do rei. No Reino Médio, ela passa a proteger os mortos. No Reino Novo, ganha força sua associação com Rá e como uma importante deusa que combate os inimigos do deus sol. Posteriormente, ela é associada à maternidade e à proteção das mulheres grávidas.

Essa mistificação do pensamento religioso da sociedade egípcia evidencia que, no período da produção do filme, alguns conceitos ainda não estavam estabelecidos nas bases teóricas e metodológicas do estudo desta civilização. O que evidencia para os alunos que o conhecimento histórico está em constante transformação e o passado não é estático, pois se redefine por meio de diferentes interpretações dos historiadores. A utilização de "A múmia" como fonte, também permite 0 entendimento da necessidade de um vocabulário adequado para uma compreensão mais ampla dos contextos históricos.

O ensino das religiosidades também apresenta um vocabulário específico para o qual 0 docente deve estar atento. A compreensão das vertentes religiosas se dá através dos conceitos e expressões linguísticas próprias de suas dinâmicas. Um grave erro é homogeneizar o vocabulário pelo viés do que é de maior lógica para os alunos. Dizer, por exemplo, que os egípcios acreditavam em ressurreição, enquanto ressuscitar é uma expectativa dos monoteístas. Cada vertente religiosa contém um conjunto de conceitos e vocábulos particulares e precisa ser compreendida através dos mesmos, o que permite um estudo para além dos limites da história, pois amplia a compreensão linguística e antropológica dos alunos. As religiosidades devem ser identificadas pelo vocabulário específico que as caracteriza. (LIA, 2012, p. 556)

Para o estabelecimento do debate após a exibição do filme, devem ser priorizadas algumas categorias de análise. Segundo Bastos (2012), a crítica à produção deve passar pelo reconhecimento do conteúdo, pela análise do roteiro e das imagens, o que se encaixa perfeitamente como estratégia para utilização de "A múmia". Destaca-se que esta película não deve ser utilizada para introduzir o conteúdo de Egito antigo, mas sim como mecanismo de fechamento ou de avaliação do mesmo; permitindo ao aluno que, de posse de conhecimentos, seja capaz de realizar o exercício de análise proposto.

O filme "A múmia" pode ser dividido em três eixos de análise: quanto ao conteúdo, identificando a abordagem histórica da temática, com suas contribuições e distorções; com relação ao roteiro, percebendo como a narrativa foi conduzida e as estratégias utilizadas pela mesma para promover uma atmosfera mística em torno da religiosidade egípcia; e com enfoque nas imagens, observando as representações da cultura do Egito antigo no início do século $X X$.

Importante estimular os alunos a manterem a atenção às três esferas de análise, já que as imagens tendem a ser mais estimulantes. Daí retoma-se a importância da ficha de apresentação prévia do filme, que possibilita orientar para questões de análise que poderiam passar despercebidas pelos discentes. Das contribuições do grupo de estudantes, com as questões mais destacadas pelos mesmos após a exibição da película é possível construir um instrumento de análise da mesma que, turma a turma vai sendo reelaborado e complexificado.

Os pontos que, de forma recorrente, mais chamam a atenção dos alunos e que corroboraram para a construção da ficha de análise, centram-se nos seguintes aspectos: as técnicas arqueológicas dos anos de 1930 e a transformação das mesmas; 
as discussões sobre 0 destino dos artefatos encontrados, início da disputa pelos acervos entre os museus europeus versus asiáticos e africanos; a simbologia de diferentes imagens apresentadas; a mistificação da religiosidade egípcia, em especial, com a presença do ocultismo e das maldições; as representações do Egito antigo e contemporâneo.

Outro aspecto frequentemente identificado pelos discentes é a presença de imagens mais adequadas no filme de 1932, do que em produções mais recentes e enriquecidas de efeitos especiais. Por exemplo, os Pergaminhos de Thot estão representados em um rolo de papiro, diferentemente de outros filmes sobre a temática, nos quais o Livro dos Mortos aparece como uma obra encadernada e com um segredo na capa. Além disso, o Livro dos Mortos nunca foi a obra que traria uma pessoa de volta a vida, mas os Pergaminhos de Thot, outro ganho de "A múmia".

A imagem de Ísis aparece, de forma correta, associada como símbolo de proteção a vida, ao contrário das produções recentes que utilizam a ankh, que é o amuleto do pós morte. O escravo egípcio aparece representado pela figura de um núbio, que foram a maioria dos escravos na antiguidade egípcia; em geral esta representação está ligada aos hebreus. Neste trabalho de busca pela narrativa fílmica mais "fiel" a história do Egito antigo é possível desenvolver uma análise crítica sobre a recriação histórica via cinema e/ou egiptomania. E, também, estimula a pesquisa sobre o tema, numa busca pela melhor "leitura" de "A múmia".

Obviamente, os equívocos também são identificados, como a altura dos vasos canopos, o Lacre dos Setes Chacais e outras imagens que não têm correspondência direta com o que está sendo apresentado. Mas, a desconstrução de uma narrativa é uma estratégia eficaz no processo de aprendizagem e promove igual estímulo na pesquisa sobre o tema. Se a ficha de análise for distribuída antes da exibição do filme, a atenção dos discentes, além do entretenimento que o mesmo proporciona, estará voltada na identificação dos aspectos propostos.

\section{MODELO DE FICHA}

\section{ROTEIRO PARA ANÁLISE DO FILME DE KARL FREUND: "A MÚMIA" (UNIVERSAL STUDIOS, 1932)}

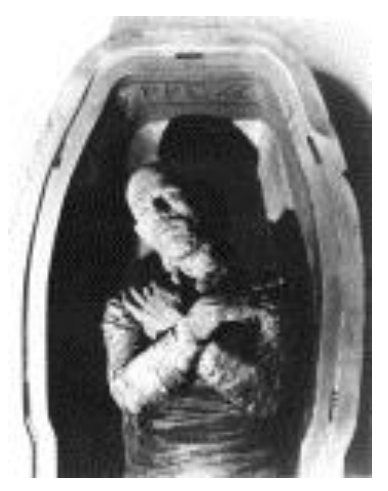

Observe os seguintes aspectos mencionados no filme:

- a possibilidade de ser enterrado vivo como "múmia";

- $\quad$ as maldições para quem abre os túmulos;

- cuidados higiênicos com os artefatos;

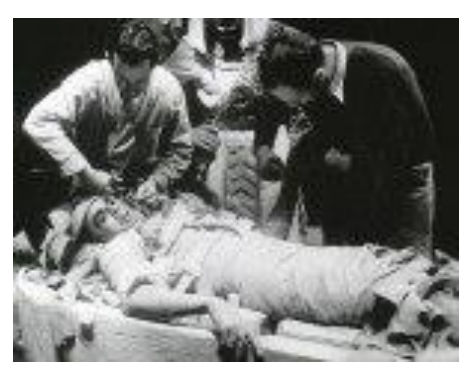

- $\quad$ discussão história \& ciência;

- $\quad$ a existência dos pergaminhos de Thot;

- o significado das imagens: Lacre dos Sete Chacais, Ísis, Ankh, Bast, Vasos Canopos, Imhotep;

- direito à realização de escavações;

- $\quad$ Museu do Cairo X Britânico;

- a crença de encontrar "pessoas perfeitas" como "múmias";

- $\quad$ o escravo núbio; 
- não ser possível ler todas as escritas egípcias;

- $\quad$ "mágica" egípcia que conduz a morte; condenação a "pior das mortes" = ser enterrado vivo;

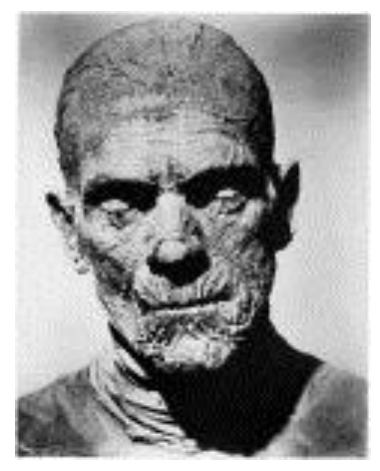

- $\quad$ quebra dos sarcófagos para apagar as palavras de retorno à vida.

\section{Da Egiptomania à Egiptologia}

O uso de fontes como recurso de ensino e pesquisa em sala de aula só tem sentido se for possível à construção de novos conhecimentos. Como alertam Seffner e Pereira (2008), o uso de fontes no ensino de História não pode servir nem como mera ilustração do conhecimento, nem como argumento de autoridade do professor ou do material didático para atesar uma ou outra versão. Pode-se acrescentar que o uso do filmes em sala de aula, especialmente em História Antiga está sempre sob o risco de reforçar e reproduzir estereótipos, generalizações e simplificações (BALÉM, 2013). Cabe ao professor propor uma abordagem fundamentada para evitar que isso aconteça. Nesse sentido, é preciso apropriar-se historiograficamente dos elementos históricos e culturais egípcios presentes no filme e que sejam relevantes para os objetivos da aula.

Em “A Múmia”, um dos casos é o do próprio personagem central. $O$ filme não se propõem a reconstituir elementos biográficos do sujeito histórico Imhotep, utilizando somente o seu nome. Isso poderia passar sem ser analisado se Imhotep não tivesse sido uma figura de grande importância ao longo de toda a história do Egito faraônico e para além dela também. Em 1928, B. J. Hurry publicou um livro em Oxford sobre Imhotep, o que significa que em 1932 já havia literatura disponível sobre o referido egípcio, a qual pode ter influenciado na escolha do nome do personagem, contribuindo para sua "imortalidade" e constante renascimento nas telas.

Entalhados no pedestal de uma estátua de Djoser (c.2667-2648 AEC), o segundo rei na III Dinastia, encontra-se a mais antiga referência a Imhotep: "O chanceler do Rei do Baixo Egito, o Primeiro após o Rei do Alto Egito, Administrador do Grande Palácio, Senhor Hereditário, Alto Sacerdote de Heliópolis, Imhotep, o Construtor, o Escultor, o Produtor de Vasos de Pedra" (RICE, 2004, p.77). É possível que ele tenha tido uma vida longeva e pode ter morrido durante o reinado do rei Huni (c.2637-2613 AEC), último rei da III Dinastia. Sua tumba nunca foi encontrada, mas especula-se que possa estar em Saqqara, perto da Pirâmide em Degraus, cuja construção foi atribuída a ele pelo sacerdote ptolomaico Manetho.

Aliás, a maior parte do que sabemos sobre Imhotep é atribuição posterior. Segundo Josephson (2001, p.151), após sua morte, Imhotep foi venerado. Durante o Reino Novo, foi descrito como Filho de Ptah e como importante divindade de Mênfis. Também existem menções na documentação que ele possa ter escrito Textos de Sabedoria, embora eles não tenham sobrevivido. No Período Tardio a veneração se transformou em divinização e ele recebeu seus próprios templos e sacerdotes.

No final do período de reis nativos egípcios, ele foi cultuado por suas habilidades de cura. Foi este último Imhotep que os gregos conheceram, daí a sua associação com o deus grego da medicina Asclépios. Para Josephson (2001, p.152), "a reputação de Imhotep sobreviveu à era da invasão árabe no norte da África ao longo do século VII da era Comum". Muitas estátuas dele 
são do Reino Novo e há muitos bronzes votivos do Período Tardio que o representavam como um escriba: de cabeça raspada, sentado e com rolos de papiro sobre os joelhos.

Considerando o contexto da repercussão da descoberta do rei menino, Tutankhamon também ganha importância em "A Múmia", mas de forma indireta. Quem sobressai-se é sua esposa Ankhesenamun que, no filme, reencarnou como Helen. Ela é perseguida por Ardeth Bay, nome escolhido por Imhotep após seu retorno à vida, como forma de manter sua condição incógnita. Os holofotes tenderam e tendem a se manter em Tutankhamon, mas ele foi um faraó com pouca ou nenhuma importância histórica. É em seu reinado que a cidade de Amarna e o deus sol Átom, anteriormente elevado a deus único, são abandonados. Os poderosos oficiais e membros da família real foram personagens mais ativos no contexto de retorno à ortodoxia religiosa do que o rei, então um menino de cerca de dez anos.

Já Ankhesenamun, longe da imagem de princesa frágil, como o filme faz transparecer, teve um importante papel nos rumos em que o Egito estava por tomar em sua época. Segundo Rice (2004, p.22-23), após a morte de Tutankhamon, ela ficou em uma posição perigosa, pois era filha de Nefertiti e Akhenaton e descendente de poderosos reis da XVIII Dinastia, como Kamose e Ahmose. Sem um herdeiro masculino ao trono, ela escreve ao rei dos hititas Suppiluliuma, pedindo que ele enviasse um de seus filhos para casar-se com ela e tornar-se rei do Egito. $O$ rei aceitou a oferta e enviou seu filho Zennanza, mas ele foi morto no caminho. Depois disso ela desaparece da História. O oficial Ay assume o poder por um breve período e, em seguida, o general Horemheb, que dá início às ações de apagamento da memória de Amarna.

Talvez um elemento ainda mais central seja a ideia do que é uma múmia e o que ela implica na religião egípcia. As vezes o senso comum deixa transparecer que, no antigo Egito, todas as pessoas eram mumificadas e que os egípcios viviam com a perspectiva de que elas voltariam à vida. Isto é uma invenção moderna feita especialmente por meio da literatura e do cinema e que atesta, por um lado, o desconhecimento sobre as crenças e práticas funerárias egípcias e, por outro, a adaptação e criação deliberadas para atingir determinados públicos.

É preciso ter em mente que "múmia" é algo que possui historicidade e não pode ser simplificada ou generalizada de uma mesma forma para toda a experiência histórica egípcia. Como explica David (2011), ainda em períodos PréDinasticos, os egípcios passaram a prestar atenção às mumificações naturais que aconteciam nos corpos enterrados no solo desértico. Em algum momento, a mumificação foi integrada às práticas funerárias e a preservação do corpo tornou-se uma condição essencial para a sobrevivência do espírito após a morte. Esse processo, no início, era simples e restrito.

No Reino Antigo, somente o rei tinha acesso à imortalidade e ao renascimento eterno através do culto de Rá, como mostram as inscrições chamadas de Textos das Pirâmides, então somente ele tinha o corpo mumificado. Se fosse de sua vontade, ele permitia que membros da família real tivessem seus corpos embalsamados e que construíssem tumbas próximas a real para também desfrutar da imortalidade. Conforme as crenças iam se consolidando, as técnicas de preservação do corpo também foram se aprimorando.

No final do Reino Antigo, pessoas de fora da família real também passaram a ter aspirações à eternidade, especialmente a partir do culto a Osíris. No Reino Médio, pessoas que pudessem arcar com os custos de uma tumba, de um funeral e de um ataúde, com as inscrições chamadas Textos dos Sarcófagos e com os custos da mumificação, poderiam ter acesso à imortalidade 
(JOÃO, 2008). No Reino Novo, as técnicas foram desenvolvidas ao máximo e um número maior de pessoas tiveram acesso à mumificação.

chamado Livro dos Mortos fornecia encantamentos e mostrava os caminhos para a alma do falecido chegar ao tribunal de Osíris e ter seu coração posto na balança e pesado em relação à pena de Maat.

Mesmo que seu coração passasse no teste e ele adentrasse no Dwat, o mundo dos mortos egípcio do período, se seu corpo não estivesse preservado, seu espirito morreria. Então, como forma de aumentar a segurança e de dar garantias de que o espirito não sofreria com a eventual destruição de seu corpo mumificado, antes de morrer, o sujeito tomava outras atitudes, como mandar confeccionar estátuas de si para servirem como morada de seu ka (energia vital, princípio do sustento), pintar cenas do seu cotidiano e escrever seu nome nas paredes da tumba ${ }^{5}$. Sendo assim, será que o Imhotep do filme teria sido realmente desaparecido com a queima do papiro e a destruição do seu corpo? E, se os egípcios quisessem amaldiçoar Imhotep, será que eles não prefeririam simplesmente destruir o corpo em vez de mumificá-lo?

$\mathrm{Na}$ sua forma mais elaborada, a mumificação consistia, resumidamente, na extração das vísceras e o seu correto acondicionamento nos jarros canópicos, na dissolução e retirada do cérebro, em banhos com ervas. O corpo e o coração eram cobertos por natrão por dezenas de dias para a extração dos líquidos corpóreos restantes. Após novos banhos e rituais de purificação e proteção, o coração era recolocado na cavidade torácica (ou substituído

\footnotetext{
${ }^{5}$ Os egípcios acreditavam que o ser era composto por diversas partes que tinham de ser preservadas da mesma forma que 0 corpo. Nesse sentido, também serviam de proteção. Caso o corpo fosse destruído, ainda havia outras partes do ser vivas. Segundo Santos, "nesta concepção plural encontramos uma diferença entre as partes que são físicas e outras não-físicas, segundo nossa classificação moderna. Na primeira estava o corpo (djet) e o coração (ib), e na segunda, o princípio do sustento (ka), a personalidade ou princípio do movimento (ba), o nome $(r n)$ e a sombra (shwty)" (2012, p.353)
}

por um amuleto escaravelho) e o corpo era embebido no natrão, betume e outras substâncias e envolto com linho. Entre as bandagens eram colocados amuletos protegendo cada parte do corpo. Embora a mumificação fosse um importante elemento da religiosidade funerária egípcia, ela era também excludente e uma forma importante de diferenciação social.

Estado o corpo preservado, de preferência com outros elementos de segurança que seriam ativados caso o corpo fosse avariado, o morto poderia renascer. Mas esse renascimento acontecia no Oeste, ou seja, tratava-se de um renascimento do espírito. Segundo Müller (2001) no antigo Egito, vida material e vida espiritual não eram esferas separadas. Daí a necessidade, não só de preservar o corpo, como de alimentá-lo ritualisticamente e oferecer culto funerário ao morto para que ele possa ter uma vida espiritual idêntica a que ele teve quando vivo, inclusive interagindo com os vivos. Embalsamar o corpo, para os egípcios, era sinônimo de que o espirito sobreviveria. A ideia aterrorizante de ser mumificado, especialmente se o sujeito ainda estivesse vivo, é um medo contemporâneo e deve ser analisado como tal, buscando compreender seu emprego no filme e a distância desta ideia em relação às crenças egípcias.

\section{Considerações finais}

O Egito está por toda a parte. Está no cinema, na literatura, nos games, nas séries de televisão, na arquitetura, no imaginário popular e até, pode-se arriscar dizer, na memória coletiva. Muitas vezes, é através destes produtos culturais que as pessoas têm os primeiros contatos com o mundo egípcio antigo. Eventualmente, esses conhecimentos vão ser confrontados nas aulas de História na escola. Mas, na universidade, nas turmas de licenciatura em História, no processo de formação de professores, esses conhecimentos 
prévios devem ser esquadrinhados e analisados de forma fundamentada e expandidos. Utilizar um filme como recurso didático, nesse sentido, abre as portas para análises muito profícuas.

Em um caso como o do filme "A Múmia", o que se deve buscar é a compreensão da visão de mundo implícita na fotografia, no roteiro, na construção de personagens, na elaboração das falas, no gestual e em diversos outros pontos relevantes na análise que o professor tenha em mente. Em uma segunda esfera de análise, é preciso fugir de uma abordagem simplista que vise somente ver os acertos e os erros da película e ter em mente que a obra fala tanto do seu tema, quanto do seu presente.

E nesse presente estão incluídos elementos contextuais e tecnológicos da produção fílmica e uma concepção estética que foram projetadas no tema. Sobre o tema, também é preciso um diálogo com a história da Arqueologia e da Egiptologia de forma a compreender quais eram as prioridades e os silêncios da ciência na época, o que se sabia sobre o assunto e de que forma isso foi empregado no filme.

Interessante que, apesar de ter sido produzido em 1932, "A múmia" é sempre atual, por constituir-se como fonte para o estudo da História e pela temática do mesmo estar em constante renovação em seu contato com a sociedade contemporânea, como por meio da egiptomania, por exemplo.

Nos últimos meses, novas notícias voltam a contemporanizar a abrangência da discussão proposta no filme. Na década de 1930, questionava-se a legitimidade dos arqueólogos europeus escavar os artefatos egípcios e os enviar a museus na Europa. Neste processo, na época, era proibida a realização de escavações pela sociedade local, sem a orientação de uma expedição europeia. A justificativa se dava pela tentativa de evitar saques.
Em junho de 2016, a revista National Geographic publicou a matéria "Ladrões de História: o saque de antiguidades agora financia o terrorismo", na qual relata que, com o esvaziamento das expedições arqueológicas na África e na Ásia, por questões de segurança, as comunidades locais empobrecidas passaram a dedicar-se a busca por artefatos da antiguidade. Para isto, utilizam-se dos sítios demarcados pelos pesquisadores e, por meio de pás e picaretas, escavam procurando peças que possam trazer retorno financeiro.

Estas, em geral danificadas pela falta de técnica na sua retirada do local, são vendidas ilegalmente a particulares, que ajudam a financiar o terrorismo internacional. Imagens analisadas pela egiptóloga Sarah Parcak, de ataúdes quebrados e ossos humanos, provavelmente provenientes das tumbas violadas, espalhados pelas areias do deserto ilustram o texto da publicação.

O debate de 1932 retorna com fôlego ao século $\mathrm{XXI}$. As dúvidas sobre a quem cabe à legitimidade de escavar e a quem cabe o direito de acolher os artefatos ganham uma nova dimensão. A posse sobre a história do Egito antigo renasce no complicado contexto das atividades terroristas do século XXI. Assim, Imhotep continua renascendo na sala de aula e com ele toda a discussão sobre o destino dos acervos da antiguidade e sua compreensão na contemporaneidade.

\section{Referências}

BAKOS, Margaret. Um olhar sobre o antigo Egito no Mundo Novo: a Biblioteca Pública do Estado do Rio Grande do Sul, 1922. Estudos Íbero-Americanos, v.27, n.2, p.153-172. dez. 2001.

BALÉM, Wellington Rafael. Antiguidade grega como um instrumento de compreensão do presente: análise de uma prática. Revista 
Latino-Americana de História, v.2, n.6, ago. 2013.

BARROS, José d'Assunção. Cinema e história: entre expressões e representações. In.: NÓVOA, Jorge, BARROS, José D'Assunção Barros (org.). Cinema-história: teoria e representações sociais no cinema. 3 ed. Rio de Janeiro: Apicuri, 2012.

BRIER, Bob. The Mummy goes to the cinema. In: BRIER, B. Egyptomania: our tree thousandyear obsession with the land of the pharaohs. New York: Palgrave Macmillan/St. Martin's Press LLC, 2013.

CASTRO, Nilo A. P. de, BONOW, Stefan Chamorro, LUCAS, Taís Campelo. Imagens da História na Indústria Cinematográfica. In.: PADRÓS, Enrique Serra (org.). Ensino de história: formação de professores e cotidiano escolar. Porto Alegre: EST, 2002.

DAVID, Rosalie. Religião e Magia no Antigo Egito. Rio de Janeiro: Bertrand Brasil/Difel, 2011.

EL-DORY, Menna. The Mummy in the movies. In: http://www.arabworldbooks.com/egyptomani a/mummy.htm, acesso em 10 ago. 2016.

FERRO, Marc. Cinema e História. São Paulo: Paz e Terra, 1992.

GLYN, Basil. Preserved on film: The Mummy, silent cinema and Egyptomania. In: Screen Studies Conference, 2 a 4 de julho, Universidade de Glasgow, 2004. Disponível em: http://eprints.mdx.ac.uk/18068/, acesso em 10 ago. 2016.

JOÃO, Maria Thereza David. Dos Textos das Pirâmides aos Textos dos Sarcófagos: a "democratização da imortalidade" como um processo sócio-político. 2008. Dissertação (Mestrado) - Programa de Pós-Graduação em História da Universidade Federal Fluminense, Niterói, 2008.

JOSEPHSON, Jack A. Imhotep. In. REDFORD, Donald B. (ed.). The Oxford Encyclopedia of Ancient Egypt. New York: Oxford University Press, 2001. v.2.

LIA, Cristine Fortes. História das religiões e religiosidades: contribuições e novas abordagens. In. Aedos. V.4. n. 11, 2012. Disponível

em: http://seer.ufrgs.br/aedos/article/view/31208/ 20886

MORETTIN, Eduardo. O cinema com fonte histórica na obra de Marc Ferro. In.: CAPELATO, Maria Helena [et al.] (org.).
História e cinema: dimensões históricas do audiovisual. 2 ed. São Paulo: Alameda, 2011.

MUELLER, Tom. Ladrões do passado. In.: National Geographic. São Paulo, junho de 2016.

MÜLLER, Maya. Afterlife. In. REDFORD, Donald B. (ed.). The Oxford Encyclopedia of Ancient Egypt. New York: Oxford University Press, 2001. v.1.

NÓVOA, Jorge, BARROS, José D'Assunção . Prefácio à terceira edição. In: NÓVOA, Jorge, BARROS, José D'Assunção Barros (org.). Cinema-história: teoria e representações sociais no cinema. 3 ed. Rio de Janeiro: Apicuri, 2012.

SEFFNER, Fernando; PEREIRA, Nilton Mullet. O que pode o ensino de História? Sobre o uso de fontes na sala de aula. Anos 90, Porto Alegre, v.15, n.28, p.113-128, dez. 2008.

RICE, Michael. Who's who in Ancient Egypt. London and New York: Taylor \& Francis eLibrary, 2004.

SANTOS, Moacir Elias. Jornada para a Eternidade: as concepções de vida post-mortem real e privada nas tumbas do Reino Novo - 15501070 a.C. 2012. Tese (Doutorado) Programa de Pós-Graduação em História, Universidade Federal Fluminense, Niteroi, 2012.

WILKINSON, Richard. The Complete Gods and Goddesses of Ancient Egypt. London: Thames \& Hudson, 2003. 